\title{
Pengaruh Budaya Organisasi dan Motivasi terhadap Kepuasan Kerja Karyawan PT Pacific Multindo Permai
}

\author{
Novira Hajani dan Kurniati W Andani \\ Program Studi Manajemen Fakultas Ekonomi dan Bisnis \\ Universitas Tarumanagara \\ Email: vira6116@gmail.com
}

\begin{abstract}
The purpose of this research is to analyse the influence of organizational culture and motivation on job satisfaction. The population of this research is all of the PT Pacific Multindo Permai employees amounted to 53 people. Sample was selected using total sampling method which means all of the population. Data processing techniques using structural equation modelling which assisted by SmartPLS Version 3 for Mac program. The result of this study reveals that organizational culture and motivation have a positive and significant effect on job satisfaction.
\end{abstract}

Keywords: Organizational Culture, Motivation, Job Satisfaction

\begin{abstract}
Abstrak: Tujuan dari penelitian ini adalah untuk mengetahui pengaruh budaya organisasi dan motivasi terhadap kepuasan kerja. Populasi yang diambil dari penelitian ini adalah seluruh karyawan PT Pacific Multindo Permai yang berjumlah 53 orang. Sampel yang dipilih menggunakan total sampling yaitu seluruh jumlah populasi. Teknik pengolahan data menggunakan structural equation modelling yang dibantu dengan program SmartPLS Versi 3 untuk Mac. Hasil dari penelitian ini yaitu budaya organisasi dan motivasi berpengaruh positif dan signifikan terhadap kepuasan kerja.
\end{abstract}

Kata Kunci: Budaya Organisasi, Motivasi, Kepuasan Kerja

\section{LATAR BELAKANG}

Semua organisasi baik berskala besar maupun kecil akan selalu menggunakan empat jenis sumber daya, sumber daya manusia salah satunya. Sumber daya manusia yang diisi oleh tenaga kerja merupakan kunci kesuksesan suatu organisasi. Sumber daya manusia yang baik tentu akan menghasilkan kinerja perusahaan yang baik pula. Oleh karena itu, organisasi atau perusahaan harus memperhatikan kepuasan kerja karyawannya agar karyawan dapat melaksanakan tanggung jawabnya dan memberikan yang terbaik untuk perusahaan.

Menurut Robbins (1998) kepuasan kerja adalah sikap karyawan terhadap pekerjaannya. Karyawan dengan kepuasan kerja yang tinggi memiliki sikap positif terhadap pekerjaannya dan bekerja dengan giat. Sedangkan karyawan yang tidak puas akan pekerjaannya, cenderung memiliki sikap negatif terhadap pekerjaannya. Kepuasan kerja didorong oleh beberapa faktor, salah satunya adalah budaya organisasi. Budaya organisasi mencerminkan jati diri perusahaan yang memiliki kekuatan sistem dan kepercayaan yang dianut bersama untuk mendorong dan meningkatkan produktivitas perusahaan baik dalam jangka pendek maupun jangka panjang.

Layaknya manusia, organisasi memiliki beragam kepribadian. Ada yang kaku atau fleksibel, ada yang tidak bersahabat maupun sifatnya membangun, ada yang inovatif maupun konservatif. Itulah mengapa budaya organisasi penting untuk mengukur kepuasan kerja karyawan. Karena budaya organisasi yang sifatnya kuat dan membangun menghasilkan 
perasaan positif karyawan terhadap perusahaan dan bisa meningkatkan produktivitas perusahaan tersebut.

Selain budaya organisasi, motivasi merupakan faktor pendorong kepuasan kerja. Menurut Heller (dalam Wibowo, 2016) motivasi adalah keinginan untuk bertindak. Setiap individu harus bisa memenuhi kebutuhan hidupnya, untuk memenuhi kebutuhan tersebut yang harus dilakukan adalah bekerja. Motivasi merupakan dasar individu bekerja. Jika individu tersebut merasa termotivasi maka ia mampu menyelesaikan pekerjaannya. Individu yang merasa termotivasi akan bertanggung jawab dan mampu mengerjakan pekerjaannya dengan baik. Individu atau karyawan yang termotivasi sangat penting untuk memasok organisasi dengan inisiatif baru yang penting dalam dunia yang penuh dengan kompetisi. Penting bagi perusahaan untuk mengidentifikasi apa yang membuat karyawan termotivasi dalam melaksanakan pekerjaannya.

Karyawan yang puas dengan pekerjaannya dapat dilihat dari tingkat kehadirannya, membangun hubungan yang baik antar sesama rekan maupun atasan, dan ikut terlibat didalam keberlangsungan perusahaan. Sebaliknya, karyawan yang tidak puas dengan pekerjaannya dapat dilihat dari komunikasi antar karyawan atau terhadap atasan yang buruk, mudah marah saat bekerja, cenderung tidak maksimal dalam bekerja akibatnya produktivitas perusahaan pun terancam apabila seorang karyawan tidak puas dengan pekerjaannya.

\section{Kajian Teori}

\section{Budaya Organisasi}

Menurut Schein (1990) budaya organisasi adalah suatu corak dari asumsi-asumsi dasar yang ditemukan atau dikembangkan oleh sebuah kelompok tertentu untuk belajar mengatasi maslah-masalah kelompok dari adaptasi eksternal dan integrasi internal yang telah bekerja dengan baik. Menurut Robbins (1993) budaya organisasi adalah sebuah persepsi umum yang dipegang teguh oleh anggota organisasi dan menjadi sebuah sistem yang memiliki pengertian secara kebersamaan.

Berdasarkan pendapat dari para ahli diatas dapat disimpulkan bahwa budaya organisasi adalah nilai, norma dan kepercayaan yang dijunjung tinggi oleh organisasi dan bersifat sebagai identitas diri bagi anggota organisasi dan dianggap sebagai karakteristik yang membedakan dengan organisasi lain.

\section{Faktor yang Mempengaruhi Budaya Organisasi}

1. Komunikasi

2. Motivasi

3. Karakteristik Organisasi

4. Proses Administrasi

5. Struktur Organisasi

6. Gaya Manajemen

\section{Motivasi}

Menurut Greenberg \& Baron (dalam Wibowo 2016) motivasi adalah serangkaian proses yang membangkitkan, mengarahkan dan menjaga perilaku manusia menuju pada pencapaian tujuan. Membangkitkan berhubungan dengan energi dibalik tindakan. Motivasi juga memegang peran penting dibalik pilihan dan arah perilaku seseorang. Sedangkan perilaku menjaga atau memelihara seorang individu untuk berusaha mencapai tujuannya. Sementara itu Menurut Kreitner \& Kinicki (2001, dalam Wibowo 2016) motivasi adalah proses psikologis yang membangkitkan dan mengarahkan perilaku dan pencapaian tujuan atau goal- 
directed behaviour. Manajer perlu memahami proses psikologis ini apabila mereka ingin berhasil membina pekerja menuju pada tujuan organisasi.

Berdasarkan pendapat ahli diatas dapat disimpukan bahwa motivasi merupakan dorongan terhadap serangkaian proses perilaku manusia pada pencapaian tujuan. Sedangkan elemen yang terkandung dalam motivasi meliputi unsur membangkitkan, mengarahkan, menjaga, menunjukkan intensitas, bersifat terus-menerus dan adanya tujuan.

\section{Tujuan Motivasi}

Hasibuan (2014) menyatakan bahwa tujuan pemberian motivasi adalah sebagai berikut:

1. Meningkatkan moral dan kepuasan kerja

2. Meningkatkan produktivitas karyawan

3. Mengefektifkan pengadaan karyawan

4. Meningkatkan loyalitas, kreativitas dan partisipasi karyawan

5. Meningkatkan efisiensi penggunaan alat-alat dan bahan baku

6. Menciptakan suasana dan hubungan kerja yang baik

7. Meningkatkan kedisiplinan serta menurunkan tingkat absensi

8. Meningkatkan kesejahteraan karyawan

9. Mempertinggi rasa tanggung jawab karyawan terhadap tugasnya

10. Mempertahankan kestabilan karyawan perusahaan

\section{Kepuasan Kerja}

Menurut Kreitner \& Kinicki (dalam Wibowo, 2016) kepuasan kerja adalah respon affective atau emosional terhadap berbagai segi pekerjaan seseorang yang berarti kepuasan kerja atau job satisfaction bukan merupakan konsep tunggal. Seseorang dapat merasa puas secara relatif dengan salah satu aspek pekerjaan dan tidak puas dengan satu atau aspek lainnya. Menurut Gibson, Ivancevich \& Donnelly (2000, dalam Wibowo, 2016) yang menyatakan bahwa kepuasan kerja adalah hasil dari persepsi tentang pekerjaan individu. Dapat disimpulkan bahwa kepuasan kerja adalah suatu sikap puas atau tidak puas atas pekerjaan yang dilaksanakan oleh karyawan yang secara langsung berpengauruh terhadap produktifitas organisasi.

\section{Faktor yang mempengaruhi kepuasan kerja}

Kreitner dan Kinicki (2010 dalam Wibowo, 2016) menyatakan bahwa terdapat lima faktor yang dapat mempengaruhi munculnya kepuasan kerja, yaitu:

1. Need fulfillment

2. Need Attainment

3. Discrepancies

4. Equity

5. Dispositional/genetic components

\section{Kaitan Antar Variabel}

Budaya organisasi yang menjadi pengikat nilai-nilai serta norma yang berlaku akan membedakan suatu organisasi dengan organisasi lainnya, oleh karena itu perusahaan dengan budaya organisasi yang kuat dapat membantu tercapainya tujuan organisasi. Budaya organisasi yang diciptakan oleh perusahaan akan dijadikan pijakan dalam beraktivitas oleh anggota organisasi yang pada nantinya membangkitkan semangat dalam bekerja dan 
memberikan kepuasan kerja kepada karyawan. Dalam melaksanakan pekerjaan, tidak semua karyawan dapat menyelesaikannya dengan baik dan terkadang tidak sesuai dengan harapan organisasi sehingga motivasi tersebut mampu membuat karyawan merasa puas dengan pekerjaan yang dilakukan. Karyawan yang merasa termotivasi akan berusaha untuk bekerja sungguh-sungguh dan bertanggung jawab atas pekerjaanya. Motivasi dapat digunakan sebagai pendorok agar bekerja secara efektif dan mencapai kepuasan kerja.

\section{Kerangka Pemikiran}

Dalam kerangka pemikiran ini, peneliti akan menggambarkan alur keterkaitan variabel independen yaitu Budaya Organisasi dan Motivasi dengan variabel dependen yaitu Kepuasan Kerja sebagai berikut:

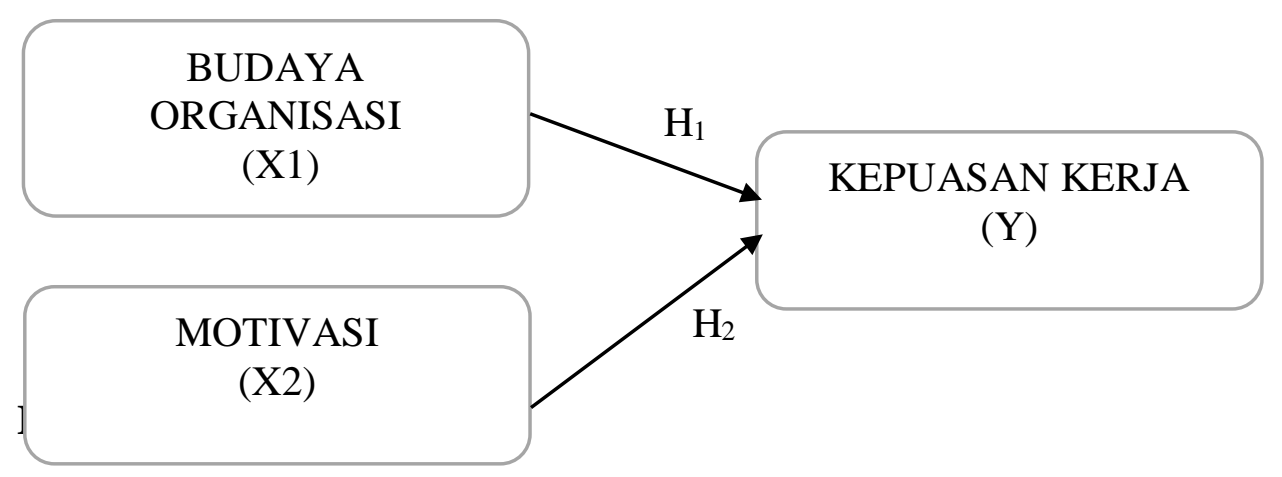

Berdasarkan pembahasan dalam tinjauan pustaka, maka peneliti merumuskan hipotesis untuk menguji kebenaran penelitian ini ke dalam berikut:

Berdasarkan pembahasan dalam tinjauan pustaka, maka peneliti merumuskan hipotesis untuk menguji kebenaran penelitian ini ke dalam berikut:

$\mathrm{H}_{1}$ : Terdapat pengaruh positif dan signifikan budaya organisasi dan kepuasan kerja

$\mathrm{H}_{2}$ : Terdapat pengaruh positif dan signifikan motivasi dan kepuasan kerja

\section{METODOLOGI}

Penelitian ini adalah penelitian asosiatif kausalistik. Menurut Sugiyono (2016) Penelitian asosiatif kausalistik bertujuan untuk mengetahui hubungan sebab-akibat antara dua variabel atau lebih. Penelitian ini dilakukan untuk menguji pengaruh budaya organisasi dan motivasi terhadap kepuasan kerja karyawan. Penelitian ini menggunakan data primer yang diperoleh melalui penyebaran kuesioner. Populasi dalam penelitian ini, peneliti memilih seluruh karyawan PT Pacific Multindo Permai sebanyak 53 orang karyawan. Teknik pengumpulan data yang digunakan dalam penelitian ini yaitu total sampling. Seluruh sampel yang digunakan dalam penelitian ini seperti yang sudah dijelaskan sebelumnya yaitu seluruh jumlah populasi.

\section{HASIL UJI STATISTIK}

\section{Hasil Uji Validitas}

Data penelitian dapat dikatakan valid apabila hasil dari uji validitas dengan menggunakan loading factors $>0,50$ dan validitas diskriminan yang di ukur dengan 
menggunakan cross loading > 0,50. Berikut ini adalah tabel yang menunjukkan hasil outer loading dan discriminant validity yang diolah dengan menggunakan program SmartPLS Ver 3 for Mac

Tabel 1. Outer Loadings

\begin{tabular}{|l|l|l|l|}
\hline & Budaya Organisasi & Motivasi & Kepuasan Kerja \\
\hline BO1 & 0,718 & & \\
\hline BO2 & 0.840 & & \\
\hline BO3 & 0.693 & & \\
\hline BO4 & 0.604 & & \\
\hline BO5 & 0.786 & & \\
\hline KK1 & & & 0.658 \\
\hline KK2 & & & 0.739 \\
\hline KK3 & & & 0.767 \\
\hline KK4 & & & 0.681 \\
\hline KK5 & & & 0.699 \\
\hline KK6 & & & 0.752 \\
\hline KK7 & & 0.683 & 0.727 \\
\hline M1 & & 0.697 & \\
\hline M2 & & 0.723 & \\
\hline M3 & & 0.577 & \\
\hline M4 & & 0.845 & \\
\hline M5 & & & \\
\hline
\end{tabular}

Sumber: olahan data SmartPLS Ver 3 for Mac (2020)

Tabel di atas menunjukkan bahwa loading factors menunjukkan nilai diatas nilai yang telah ditetapkan sebesar $>0,5$. Pada tabel diatas terlihat bahwa nilai tertinggi sebesar 0.845 yaitu indikator M5 (Motivasi). Hal ini menunjukkan bahwa semua indikator dalam penelitian ini dinyatakan valid atau sah dan telah memenuhi persyaratan uji validitas,

Tabel 2. Discriminant Validity

\begin{tabular}{|l|l|l|l|}
\hline & $\begin{array}{l}\text { Budaya } \\
\text { Organisasi }\end{array}$ & $\begin{array}{l}\text { Kepuasan } \\
\text { Kerja }\end{array}$ & Motivasi \\
\hline Budaya Organisasi & 0.733 & & \\
\hline Kepuasan Kerja & 0.743 & 0.710 & 0.710 \\
\hline Motivasi & 0.710 & 0.822 & \\
\hline
\end{tabular}

Sumber: Olahan data SmartPLS Ver 3 for Mac (2020)

Tabel diatas menunjukkan bahwa cross loading menunjukkan nilai datas nilai yang ditetapkan yaitu sebesar $>0,50$ yang artinya semua indikator dalam penelitin ini dinyatakan valid atau sah dan telah memenuhi persyaratan uji validitas.

\section{Hasil Uji Reliabilitas}

Tabel 3. Cronbach's Alpha 


\begin{tabular}{|l|l|}
\hline & Cronbach's Alpha \\
\hline Budaya Organisasi & 0.782 \\
\hline Kepuasan Kerja & 0.843 \\
\hline Motivasi & 0.750 \\
\hline
\end{tabular}

Sumber: Olahan data SmartPLS Ver 3 for Mac (2020)

Tabel di atas memperlihatkan bahwa cronbach's alpha menunjukkan nilai semua konstruk > 0,60 sehingga nilai konstruk tersebut dinyatakan reliabel.

Tabel 4. Composite Reliability

\begin{tabular}{|l|l|}
\hline & Composite Reliability \\
\hline Budaya Organisasi & 0.851 \\
\hline Kepuasan Kerja & 0.882 \\
\hline Motivasi & 0.834 \\
\hline
\end{tabular}

Sumber: Olahan data SmartPLS Ver 3 for Mac (2020)

Tabel di atas memperlihatkan bahwa composite reliability menunjukkan nilai semua konstruk $>0,70$ sehingga nilai konstruk tersebut dinyatakan reliabel.

\section{Uji Koefisien Determinasi $\left(\mathbf{R}^{2}\right)$}

Tabel 5. $R$-square Adjusted

\begin{tabular}{|l|l|l|}
\hline & R Square & R Square Adjusted \\
\hline Kepuasan Kerja & 0.727 & 0.716 \\
\hline
\end{tabular}

Sumber: Olahan data SmartPLS Ver 3 for Mac (2020)

Tabel di atas dapat dijelaskan bahwa budaya organisasi dan motivasi kerja memiliki pengaruh yang kuat terhadap kepuasan kerja yakni sebesar 71,6\% sedangkan sisanya sebesar $28,4 \%$ dipengaruhi oleh variabel lain yang tidak terdapat pada penelitian ini. Hal ini juga menjelaskan bahwa apabila variabel budaya organisasi dan motivasi mengalami perubahan maka variabel kepuasan kerja juga akan mengalami perubahan sebesar 71,6\%.

\section{Pengujian effect size $\left(\mathbf{f}^{2}\right)$}

Tabel 6. Effect size $\left(\mathrm{f}^{2}\right)$

\begin{tabular}{|l|l|l|l|}
\hline & $\begin{array}{l}\text { Budaya } \\
\text { Organisasi }\end{array}$ & Kepuasan Kerja & Motivasi \\
\hline Budaya Organisasi & & 0.189 & \\
\hline Kepuasan Kerja & & & \\
\hline Motivasi & & 0.640 & \\
\hline
\end{tabular}

Sumber: Olahan data SmartPLS Ver 3 for Mac (2020)

Berdasarkan tabel di atas, dapat dijelaskan bahwa nilai $\mathrm{f}^{2}$ variabel budaya organisasi terhadap variabel kepuasan kerja yaitu sebesar 0,189 yang artinya organisasi memiliki pengaruh yang sedang terhadap kepuasan kerja. Sedangkan nilai $\mathrm{f}^{2}$ variabel motivasi terhadap kepuasan kerja yaitu sebesar 0,640 yang artinya motivasi memiliki pengaruh yang besar terhadap kepuasan kerja. 
Uji Kecocokan Model (Goodness of Fit) atau (GoF)

Tabel 7. Average Variance Extracted (AVE)

\begin{tabular}{|l|l|}
\hline & Average Variancce Extracted (AVE) \\
\hline Budaya Organisasi & 0.537 \\
\hline Kepuasan Kerja & 0.516 \\
\hline Motivasi & 0.504 \\
\hline
\end{tabular}

Sumber: Olahan data SmartPLS Ver 3 for Mac (2020)

Berdasarkan tabel di atas, diketahui bahwa nilai AVE sebesar 0,519 yang didapat dari hasil penjumlahan sebagai berikut:

$\mathrm{AVE}=\frac{0.537+0.516+0.504}{3}=0.519$

Serta berdasarkan pada tabel diatas diketahui bahwa nilai $\mathrm{R}^{2}$ yakni sebesar 0,727 , maka dapat dilakukan perhitungan untuk mendapatkan besaran nilai GoF yaitu sebagai berikut:

$\mathrm{GoF}=\sqrt{A V E \times R^{2}}$

$\mathrm{GoF}=\sqrt{0,519 \times 0,727}=0,614$

Nilai dari GoF dalam penelitian ini yaitu sebesar 0,614 yang artinya bahwa tingkat kelayakan atau kecocokan model dalam penelitian in dinyatakan besar.

\section{Pengujian Hipotesis (path coefficient)}

Tabel 8. Pengujian Hipotesis (Path Coefficient)

\begin{tabular}{|l|l|l|l|l|l|}
\hline & Original & Sample & Standard & $\begin{array}{l}T \text { - } \\
\text { Statistics }\end{array}$ & P-Values \\
\hline $\begin{array}{l}\text { Budaya Organisasi } \\
\rightarrow \text { Kepuasan Kerja }\end{array}$ & 0.322 & 0.329 & 0.130 & 2.489 & 0.011 \\
\hline $\begin{array}{l}\text { Motivasi } \rightarrow \\
\text { Kepuasan Kerja }\end{array}$ & 0.593 & 0.595 & 0.122 & 4.851 & 0.000 \\
\hline
\end{tabular}

Sumber: Olahan data SmartPLS Ver 3 for Mac (2020)

Berdasarkan pada tabel 4.11 di atas, dapat dijelaskan bahwa hasil pengujian variabel budaya organisasi terhadap kepuasan kerja memiliki nilai T-Statistic sebesar 2,489> 1,96 dan nilai $P$-Values sebesar $0,011<0,05$, maka hipotesis diterima dan dapat disimpulkan bahwa terdapat pengaruh positif dan signifikan budaya organisasi dan kepuasan kerja. Sedangkan hasil pengujian variabel motivasi terhadap kepuasan kerja memiliki nilai $T$-Statistic sebesar 4,851 > 1,96 dan nilai $P$-Values sebesar $0,000<0,05$, maka hipotesis diterima dan dapat disimpulkan bahwa terdapat pengaruh positif dan signifikan motivasi dan kepuasan kerja. 


\section{PEMBAHASAN}

Hasil uji validitas dan reliabilitas dalam penelitian ini menunjukkan bahwa semua variabel yang diuji valid atau sah dan reliabel. Variabel dikatakan valid karena nilai dari tiap loading factors dari pernyataan tiap indikator $>0,50$ dan dikatakan reliabel karena nilai dari tiap cronbach's alpha >0,60 serta composite validity dari tiap indikator $>0,70$. Hal ini menyatakan bahwa penelitian ini layak untuk dilanjutkan ke analisis selanjutnya.

$R$-square dalam penelitian ini memperlihatkan bahwa variabel budaya organisasi dan variabel motivasi memiliki pengaruh yang kuat terhadap variabel kepuasan kerja yakni sebesar 71,6\%. Pengujian effect size $\left(\mathrm{f}^{2}\right)$ memperlihatkan bahwa variabel budaya organisasi memiliki pengaruh yang sedang terhadap variabel kepuasan kerja yakni senilai 0,189 dan juga variabel motivasi memiliki pengaruh yang besar terhadap variabel kepuasan kerja yakni senilai 0,640. Serta hasil uji kecocokan model atau GoF yang menunjukkan bahwa tingkat kelayakan atau kecocokan model penelitian ini dinyatakan layak.

Selanjutnya mengenai pembahasan dua hipotesis yang telah dibuat oleh peneliti dan telah dibahas sebelumnya bahwa pengujian menggunakan metode bootstrapping, dengan penjelasan sebagai berikut:

\section{$H_{1}=$ Terdapat pengaruh positif dan signifikan budaya organisasi dan kepuasan kerja}

Berdasarkan pada tabel, hasil pengujian hipotesis variabel budaya organisasi terhadap variabel kepuasan kerja memiliki nilai T-Statistic sebesar 2,489 dan nilai P-Values sebesar 0,011, maka dapat disimpulkan bahwa hipotesis ini diterima. Hasil hipotesis dari penelitian ini senada dengan hasil hipotesis penelitian yang dilakukan oleh Yakup (2017) dengan judul "Pengaruh Keterlibatan Kerja, Budaya Organisasi, dan Motivasi Kerja Terhadap Kepuasan Kerja Pegawai" yang menyatakan bahwa terdapat pengaruh positif dan signifikan antara budaya organisasi dan kepuasan kerja. Hal ini didukung karena dengan Budaya organisasi sebagai pegangan bagi pegawai dalam berperilaku yang menjadi pedoman dalam berinteraksi dengan sesama rekan kerja, berinteraksi dengan organisasi lain dan menjadi pedoman dalam pengambilan keputusan. Kepuasan kerja akan didapatkan jika harapan-harapan dari pekerjaannya dapat dipenuhi.

\section{$\mathrm{H}_{2}=$ Terdapat pengaruh positif dan signifikan motivasi dan kepuasan kerja}

Berdasarkan pada tabel, hasil pengujian hipotesis variabel motivasi kerja terhadap variabel kepuasan kerja memiliki nilai T-Statistic sebesar 4,851 dan nilai P-Values sebesar 0,000, maka dapat disimpulkan bahwa hipotesis ini diterima. Hasil hipotesis dari penelitian ini senada dengan hasil hipotesis penelitian yang dilakukan oleh Wahyuni (2019) dengan judul "Pengaruh Motivasi, Kompensasi dan Promosi Jabatan Terhadap Kepuasan Kerja Karyawan Starbucks di Plaza Atrium Jakarta Pusat" yang menyatakan bahwa terdapat pengaruh positif dan signifikan antara motivasi dan kepuasan kerja. Hal ini didukung karena motivasi mejadi pondasi yang kuat bagi setiap individu dalam mengeksplorasi kemampuan yang dimiliki dalam rangka meraih kebutuhan dan keinginan yang diharapkan, dengan terpenuhinya harapan-harapan yang diinginkan, maka dengan sendirinya kepuasan kerja dapat dirasakan. 


\section{KESIMPULAN DAN SARAN}

Berdasarkan pada hasil penelitian serta analisis pada bab sebelumnya maka dapat disimpulkan sebagai berikut:

1. Budaya organisasi berpengaruh positif dan signifikan terhadap kepuasan kerja karyawan PT Pacific Multindo Permai.

2. Motivasi berpengaruh positif dan signifikan terhadap kepuasan kerja karyawan PT Pacific Multindo Permai.

Terkait dengan hasil analisa yang telah dibahas sebelumnya, terdapat saran dari peneliti yang diharapkan dapat bermanfaat, yaitu agar PT Pacific Multindo Permai bisa menciptakan dan merealisasikan nilai-nilai budaya organisasi secara tertulis ke dalam peraturan kerja karyawan. Dengan demikian nilai-nilai tersebut bisa dapat disosialisasikan oleh karyawan sehingga tertanam dalam diri karyawan dan nantinya bisa meningkatkan kepuasan kerja karyawan. Selain itu, diharapkan perusahaan bisa memperhatikan dan membantu meningkatkan motivasi karyawan dilihat dari sistem pengembangan karir dan promosi yang jelas dan transparan, pemberian penghargaan atas prestasi kerja, gaji yang sesuai dengan pekerjaan hingga lingkungan yang aman dan menyenangkan bagi karyawan.

\section{REFERENSI}

Abdillah, W. \& Jogiyanto. (2015). Partial Least Square (PLS), Alternatif Structural Equation Modeling (SEM) dalam Penelitian Bisnis. Yogyakarta: Penerbit Andi.

Hasibuan, Malayu. (2012). Manajemen Sumber Daya Manusia. Jakarta: PT. Bumi Aksara.

Kreitner, Robert dan Angelo Kinicki. (2001). Organizational Behavior. New York: McgrawHill Companies, Inc.

Makmuri, Muchlas. (2005). Perilaku Organisasi. Yogyakarta: Gadjah Mada University Press.

Prayitno, Elida. (1989). Motivasi dalam Belajar. Jakarta: P2LPTK.

Robbins, S.P. (1998). Organizational Behavior: Concepts, Controversies, and Applications, Seventh Edition. Jakarta: Englewood Cliffs dan PT. Prenhallindo

Schein, Edgar H. (2004). Organizational Culture and Leadership. Third Edition. San Francisco: Jossey-Bass Publishers.

Sugiyono. (2016). Metode Penelitian Kuantitatif, Kualitatif, dan R\&D. Bandung: Alfabeta. Wibowo. (2016). Manajemen Kinerja Edisi Kelima. Jakarta: PT Grafindo Persada.

Yakup, Yakup. (2017) Pengaruh Keterlibatan Kerja, Budaya Organisasi dan Motivasi Kerja Terhadap Kepuasan Kerja Pegawai. Perisai, Vol 1 (3), October 2017. 